\title{
Risks Management of Virtual Currencies and Financial Insurance Challenges
}

\author{
Dr. Omar Shdeifat (PhD in I-Banking) \\ Expert in Crypto currencies Risk Management \\ Department of Sectorial Studies \\ Integrity and Anti-Corruption Commission \\ Jordan
}

\begin{abstract}
The study aimed mainly to examine the risks of virtual currencies and the challenges of financial insurance they encounter. Where, the study explored the most important components that affect the management of encrypted currencies risks including operational risks. While taking into account BASEL standard II/III in reducing the intensity of insurance compensations risks consequential on virtual currencies.
\end{abstract}

\section{Design/methodology/approach}

The study composed of a comprehensive review for the management of virtual currencies risks then it considered some references which tackled this subject then moving on to illustrate the mechanism of data collection and assessment of risks down to the findings. Methodology used the descriptive inductive approach through the analysis of data and information made available to the subject matter of study. Yet, as for the approach applied it was about taking a specimen from the virtual currencies to study the risks, wherein the specimen represented from (100) virtual currency out of (2079) currency allotted over (14641) market around the world.

\section{Findings}

The relation arising in the study's subject is a direct relation between the risks of virtual currencies' market value and the supply traded for them, where the relation between the price and traded supply represented the opposite of that, as the findings had established aninverse relation here and agreed with the volume traded during (24 hours), but the traded supply in virtual currencies indicated to elevated insurance risks.

Keywords: Financial risk Management, risks of virtual currencies, insurance of operations risks.

\section{Introduction}

The world has witnessed a quality leap in the spread of virtual currencies topped by BITCOIN, where virtual currencies have become tradable in many countries and used in different daily activities such as sale, purchase, bills payment and tax payment. Such dealings resulted in various risks such as forgery, fraud, embezzlement, duplicated payment [Shdeifat, 2018] and other risks encountered by virtual currencies. The main management operations of virtual currencies risks that should be highlighted are the operational risks linked to BASEL standard II and BASEL III [Yang et.al.,2017],[Peterset.al.,2016] linked also with the encrypted currencies, and so banks turned out to face different risks due to the prevalence of virtual currency, which resulted in big financial challenges calling for keeping updated with BLOCKCHAIN technology through the banks to mitigate the acuteness of such currencies' risks especially in the processes of resources-lacking funding [Bowers,2016]. The study was focused on the mechanisms of virtual currencies management through focusing on the risks concept related to virtual currencies and the challenges of insurance they face.

\section{Review of Literature}

Literature which addressed virtual currency through the studies and researches demonstrated that such currency is tradable directly without a mediator such as central and commercial banks, banking institutions where they elaborated on this subject. The researcher found, upon reviewing the literature, that some researches and studies had talked about the working mechanism of virtual currency but not about their financial risks elaborately, whereas, other researches had tackled virtual currency from the perspective of their monetary policy but hadn't tackled the challenges encountered such as insuring them. 
The study entitled: Opening discussion on banking sector risk exposures and vulnerabilities from virtual currencies: an operational risk perspective [Peters et.al., 2016], has developed the first substantial perspective for the operational risks about the main issues of risks management related to new forms of e-currency in real economy, where the study was focused on the new types of risks and development of the current types of risks, where the study showed that there are new components for the financial institutions emerged to meet the increased demand on e-money and partial payment systems, virtual currencies and encrypted currencies, where by the study of [Dr. Shdeifat] would come to determining the root causes of operational risks related to virtual and encrypted currencies and dealing with them.

The study entitled: Risks of crypto currencies: considering the inherent risks of cryptocurrency ecosystems [Weaver, 2018], has revealed the processes of encryption in four major areas they are: technical risks, economic risks, regulatory risks and social risks. Where, the study showed that the most popular encrypted currency is BITCOIN, and demonstrated the mechanisms of BITCOIN currency from how to gather the balances up to enable the BITCOIN payment system to be resilient the control. The main conclusions achieved by the study were that the risks in the free world of encryption are of multiple and diverse aspects, yet most of them are limited to their users.

\section{Data}

Researcher has used the data and information available through e-platforms specialized in virtual currencies in terms of quantity and quality, so that the selected specimen represented the study of population as a whole, and main information website was[coinmarketcap.com]. Data and information related to virtual currencies had witnessed sudden fluctuations during the past decade, where the figures of virtual currency exchange rate versus the US dollar recorded remarkable hike through the e-platforms of them [Weaver, 2018], and notwithstanding the appearance of some risks for such currencies like the exchange rate risks, yet, their trading is still on the increase across the continents of the world's countries.

Researcher has gathered the data and information related to the subject matter of study through referring to the sources and references specialized in virtual currencies, then gathered the e-data related to such currencies through the relevant e-platforms; some of these data the market value of virtual currencies, price and traded volume within 24 hours, traded supply, where the study specimen comprised (100) virtual currency being traded in the world's markets including (BITCOIN, ETHEREUM, XRP, BITCOIN Cash, EOS, Stellar, LITECOIN, Tether, CARDANO, MONERO)[DAJ,2017], and the study population included about (2079) virtual currency distributed over (14641) market spread around the world, where the market value of virtual currencies for the study's population as a whole represented US\$(209) milliard up to (15October, 2018).Yet, as for the market size during (24 hours) only it reached about US\$ (22) milliard. As the BICOIN had the higher percentage among the virtual currencies volume, hence accounted for (54.2\%). Moreover, the risk of virtual currencies Represented in Price volatility, Exchange rate risk, Future legislation, Theft and / or loss, Third party reliability, and E-commerce vulnerabilities [Grant and Hogan,2015].

\section{Methodology and estimation of the value exposed to risks}

The research followed the descriptive inductive method through the data and information made accessible to the researcher to demonstrate through that the concepts and terms connected with the subject matter of study down to analysis of such information to come up with the main indicators relating to virtual currencies. Researcher has estimated the value exposed to risks and related to virtual currencies through statistical and financial data after analyzing them using the programs dedicated to analysis down to the results intended from the study. Study model is represented in the following equation: $\mathbf{V C C S i}=\mathbf{j}+\mathbf{k M C i}+\mathbf{I P i}+\mathbf{m}(\mathbf{V} / \mathbf{2 4 h}) \mathbf{i}+\mathbf{e i}$.(1)

\begin{tabular}{|l|l|}
\hline $\mathrm{i}$ & Type of virtual currency \\
\hline $\mathrm{j}-\mathrm{m}$ & Constants \\
\hline $\mathrm{MC}$ & Market value \\
\hline $\mathrm{P}$ & Price \\
\hline V/24h & Volume of trading within (24) hours \\
\hline VCCS & Traded supply of virtual currencies \\
\hline E & Standard error \\
\hline
\end{tabular}




\section{Empirical results}

The study's specimen is represented on the risks or virtual currencies in (100) virtual currency out of (2079) currency. Where the specimen represented four (4) four components according to the following equation: VCCSi $=\mathrm{j}+\mathrm{kMCi}+\mathrm{PPi}+\mathrm{m}(\mathrm{V} / 24 \mathrm{~h}) \mathrm{i}+\mathrm{ei}$. (2) And, after conducting statistical experiments on the study's data and information the researcher came up with the following conclusions: VCCSi $=12,867,483,006+1.11 \mathrm{MCi}-$ 17,433,253Pi - 3.834(V/24h)i + ei (3) Descriptive Statistics and ANOVA

\begin{tabular}{|c|c|c|c|c|c|}
\hline & $\mathrm{N}$ & \multicolumn{2}{|c|}{ Skewness } & \multicolumn{2}{|l|}{ Kurtosis } \\
\hline & Statistic & $\begin{array}{l}\text { Statisti } \\
\text { c }\end{array}$ & $\begin{array}{l}\text { Std. } \\
\text { Error }\end{array}$ & Statistic & $\begin{array}{l}\text { Std. } \\
\text { Error }\end{array}$ \\
\hline $\mathrm{MC}$ & 100 & 9.164 & .241 & 87.854 & .478 \\
\hline $\mathrm{P}$ & 100 & 9.754 & 241 & 96.533 & .478 \\
\hline $\mathrm{V}$ & 100 & 6.179 & .241 & 39.559 & .478 \\
\hline VCCS & 100 & 5.143 & .241 & 30.794 & .478 \\
\hline \multirow[t]{2}{*}{$\begin{array}{l}\text { Valid } \\
\text { (listwise) }\end{array}$} & 100 & & & & \\
\hline & & & $\mathrm{df}$ & $\mathrm{F}$ & Sig. \\
\hline \multirow[t]{3}{*}{$\mathrm{MC}$} & \multicolumn{2}{|c|}{ Between Groups } & 98 & 175738.551 & .002 \\
\hline & \multicolumn{2}{|c|}{ Within Groups } & 1 & & \\
\hline & \multicolumn{2}{|c|}{ Total } & 99 & & \\
\hline \multirow[t]{3}{*}{$\mathrm{P}$} & \multicolumn{2}{|c|}{ Between Groups } & 98 & 69121701.368 & .000 \\
\hline & \multicolumn{2}{|c|}{ Within Groups } & 1 & & \\
\hline & \multicolumn{2}{|c|}{ Total } & 99 & & \\
\hline \multirow[t]{3}{*}{ V } & \multicolumn{2}{|c|}{ Between Groups } & 98 & 2644915.247 & .000 \\
\hline & \multicolumn{2}{|c|}{ Within Groups } & 1 & & \\
\hline & \multicolumn{2}{|c|}{ Total } & 99 & & \\
\hline
\end{tabular}

\begin{tabular}{|c|c|c|c|c|c|}
\hline \multicolumn{6}{|c|}{ Correlations } \\
\hline & & $\mathrm{MC}$ & $\mathrm{P}$ & V & VCCS \\
\hline \multirow[t]{3}{*}{$\mathrm{MC}$} & Pearson Correlation & 1 & $.970^{* * *}$ & $.792^{* *}$ & $-.027-$ \\
\hline & Sig. (2-tailed) & & .000 & .000 & .787 \\
\hline & $\mathrm{N}$ & 100 & 100 & 100 & 100 \\
\hline \multirow[t]{3}{*}{$\mathrm{P}$} & Pearson Correlation & $.970^{* * *}$ & 1 & $.736^{* *}$ & $-.040-$ \\
\hline & Sig. (2-tailed) & .000 & & .000 & .696 \\
\hline & $\mathrm{N}$ & 100 & 100 & 100 & 100 \\
\hline \multirow[t]{3}{*}{ V } & Pearson Correlation & $.792^{* * *}$ & $.736^{* * *}$ & 1 & $-.045-$ \\
\hline & Sig. (2-tailed) & .000 & .000 & & .655 \\
\hline & $\mathrm{N}$ & 100 & 100 & 100 & 100 \\
\hline \multirow[t]{3}{*}{ VCCS } & Pearson Correlation & $-.027-$ & $-.040-$ & $-.045-$ & 1 \\
\hline & Sig. (2-tailed) & .787 & .696 & .655 & \\
\hline & $\mathrm{N}$ & 100 & 100 & 100 & 100 \\
\hline
\end{tabular}

\begin{tabular}{|l|l|l|l|l|l|}
\hline \multicolumn{6}{|l|}{ Model Summary } \\
\hline Model & $\mathrm{R}$ & R Square & $\begin{array}{l}\text { Adjusted } \\
\text { Square }\end{array}$ & $\begin{array}{l}\text { Std. Error of the } \\
\text { Estimate }\end{array}$ & $\begin{array}{l}\text { Durbin- } \\
\text { Watson }\end{array}$ \\
\hline 1 & $.079^{\mathrm{a}}$ & .006 & $-.025-$ & 43628813266.997 & 2.091 \\
\hline
\end{tabular}


Where, it was found from the results that the relation is a direct one between the market value of virtual currencies and the traded supply of them, and the relation is inverse between the price and their traded supply, and also, the relation is inverse between their size within (24) hours and as well as for the traded supply. So, it can be said that the risks in virtual currencies lie in the market price and the size supplied [Lindberg; Seifert, 2015].

\section{Conclusion}

After analyzing the information and data related to the study, the researcher comes up with the following main points:

1.Risks Management of virtual currencies shall be considered an essential and effective element in maintaining the continuity of their trading.

2.Financial insurance shall be considered with a clear impact in reducing the extent of virtual currencies risks.

3. Virtual currencies are considered directly submitting to the operational risks connected with BASEL (II) and (III) standards.

4. Risks Management of BLOCKCHAIN are considered a cornerstone in maintaining the insurance pertaining to virtual currencies.

\section{References}

Bowers, Darnell (2016). Risk management : past, present and future directions, Nova publishers, New york, USA, p68.

Yang, Shirley Ou; et.al (2017). Enabling effective operational risk management in a financial institution: An action research study, Journal of management information systems, Vol.34, Issue. 3, p731.

Peters, Gareth W; et.al (2016). Opening discussion on banking sector risk exposures and vulnerabilities from virtual currencies: An operational risk perspective, Journal of banking regulation, Vol.17, Issue.4, p15-18.

Weaver, Nicholas (2018). Risks of crypto currencies: considering the inherent risks of cryptocurrency ecosystems, Communications of the ACM, Vol.61, Issue.6, p21.

DAJ, Alexis (2017). Virtual Currencies- monetary policy dilemmas and regulatory challenges, Bulletin of the Transilvania University of Brasov, Series V: Economic Sciences, Vol.10(59), Issue.2, p219.

Grant, Gerry; Hogan, Robert (2015). Bitcoin: risks and controls, journal of corporate accounting and finance (Wiley Periodicals Inc), Vol. 26, Issue. 5,p30.

Shdeifat, Omar (2018). Virtual currency technologies: Bitcoin as a model, PhD thises, Faculty of graduate studies, The world islamic science \& education university (w.i.s.e), p78.

Lindberg, Deborah L; Seifert, Deborah L (2015).Risk management in the insurance industry: A comparison of solvency II to U.S. insurance regulations,Journal of insurance issues, Vol. 38, Issue. 2, p241. 